\title{
Third-Person Perception and Health Beliefs
}

\author{
John Chapin \\ Pennsylvania State University, Monaca, USA. \\ Email: jrc11@psu.edu \\ Received March 26 ${ }^{\text {th }}, 2011$; revised May $2^{\text {nd }}, 2011$; accepted June $11^{\text {th }}, 2011$.
}

\begin{abstract}
A survey of 316 medical professionals was used to study third-person perception (TPP) within the context of a public health issue, intimate partner violence (IPV) and to explore theoretical linkage between TPP and the health belief model. Medical professionals exhibit TPP, believing they are less influenced than patients by media depictions of IPV. In terms of the Health Belief Model, one element, perceived susceptibility, emerged as a predictor of TPP.
\end{abstract}

Keywords: Third-Person Perception, Health Belief Model, Intimate Partner Violence

In lay terms, third-person perception (Davison, 1983) is the belief that media messages affect others more than they affect oneself. The phenomenon has become a mainstay of communications theory, with a growing literature documenting the impact of third-person-perception (TPP) on attitudes and behaviors (For reviews, see Conners, 2005; Golan \& Day, 2008). TPP has been documented in a number of contexts, including advertisements (Chia, 2009; Sigal, 2009), news coverage (Coe et al., 2008; Frederick \& Neuwirth, 2008), and on-line games (Boyle, McLeod, \& Rojas, 2008; Zhong, 2009).

While TPP is well established in the literature, the phenomenon remains of interest to scholars and practitioners, because people act on their perceptions. The most established attitudinal/behavioral link is the willingness to censor (Boyle, McLeod, \& Rojas, 2008; Cohen \& Weimann, 2008). For instance, college students who exhibit third-person perception regarding Internet pornography are also more willing to censor content or support stricter legislation (Zhao \& Cai, 2008). Person-perception has also been linked with a number of attitudes and behaviors, including voting decisions (Golan, Banning, \& Lundy, 2008; Jeffres et al., 2008), support for legal action (Day, 2008; Frederick \& Neuwirth, 2008), and decreased risk behaviors (Chapin, 2000; Lewis, Watson, \& Tay, 2007).

A smaller, but growing literature is exploring TPP and health. The purpose of the current study is to examine TPP within the context of a public health issue (intimate partner violence) and to explore theoretical linkage between TPP and the health belief model.

Only in recent years has the medical community begun to fully recognize intimate partner violence (IPV) as a public health crisis. According to a popular website for medical professionals (emedicinehealth.com), women in the U.S. are more likely to have been injured, raped, or murdered by a male partner than by all other types of attackers. Twice as many women report sexual assault by their husbands as report assault by strangers. Every year, about 2,000 women are murdered by their current or former male partners in the U.S. One in seven women going to the doctor's office have a history of partner abuse. One in four women seeking care in the emergency department, for any reason, is a domestic-violence survivor, and one in four women has been abused at some point in her life.
The current study surveys medical professionals about thirdperson perception, health beliefs, and IPV.

\section{TPP and Health}

While third-person perception is a broad concept, applicable to any type of media messages, only a small percentage of published findings explore TPP regarding health-related topics. A study of Chinese college students (Chia \& Wen, 2009) found TPP regarding the impact of idealized body images in advertisements. Students who exhibited higher degrees of TPP also tended to make more negative self-assessments about their own body image. The findings have clear implications for eating disorders, as well as mental health issues. Two studies (Cho \& Boster, 2008; Chock et al., 2007) documented TPP regarding anti-drug advertisements among adolescents. College students exhibiting first-person perception, the belief that oneself is more influenced by media messages than are others, also exhibit increased information seeking about bird flu (Wei, Lo, \& $\mathrm{Lu}, 2008$ ); thus TPP may be linked with more active media consumption. Another study of adolescents (Chapin, 2000) documented TPP regarding safer-sex messages. Adolescents who exhibited higher degrees of TPP were more likely to engage in sexual activity at earlier ages and less likely to use condoms during intercourse.

\section{Health Belief Model}

One of the cornerstones of health communication is the Health Belief Model (HBM). The model is a cognitive decision theory. As such, it assumes that individuals make rational decisions about their health, based on an internal cost/benefit analysis. According to the model, there are four types of health beliefs: 1) perceived susceptibility, 2) perceived severity, 3) perceived benefits, and 4) perceived barriers.

A vast literature documents the ability of the HBM to predict health behaviors. Two of the elements, perceived susceptibility and perceived severity, emerge as strong predictors. For instance, Lin, Simoni and Zemon (2005) studied sexual behaviors and HIV risk among Taiwanese college students. The rate of HIV infection in Taiwan has risen 15\% each year since 1997, ranking it among the highest in HIV/AIDS cases in Asia. Ac- 
cording to the Global Sex Survey, the Taiwanese are one of the least sexually active peoples in the world, but they engage in unprotected sex more frequently: 38\% reported having unprotected sex without knowledge of their partner's sexual history. The study reported that $57 \%$ of female and $69 \%$ of male students were sexually active. Consistent with previous surveys, only $27 \%$ of males and $18 \%$ of females reported consistent condom use; on the other end of the spectrum, $11 \%$ of males and $18 \%$ of females reported never using condoms. Elements of the HBM did not predict the number of sexual partners or the frequency of sex, but did predict consistent condom use. Students who believed they were susceptible to HIV infection, believed condoms would protect them from infection (perceived benefits), and reported fewer barriers (access to condoms, embarrassment, cost) were the most likely to use condoms consistently. Perceived severity also predicted condom use, but in the opposite direction: students who viewed HIV as a treatable condition were more likely to use condoms consistently than students who viewed AIDS as a death-sentence. A likely reason for this unexpected finding is stigma-if something is too horrible to think about-we don't.

A key to applying the HBM to IPV is understanding beliefs. A study of domestic violence in the military revealed that over half of enlisted women (57\%) support routine domestic violence screening among the ranks (Carlson et. al, 2006). Women in the military differ from civilians in that $73 \%$ of enlisted women vs $43 \%$ of civilian women believe routine screening and reporting would increase womens' risks of subsequent violent attacks. When battered women leave their abusive partners, they are at their highest risk of murder. Because the military reports domestic abuse among the ranks, the risk of violence could similarly be heightened as batterers are exposed and their careers are at stake. Several factors emerged as barriers to disclosing abuse, including perceived damage to their own or their partner's military careers, embarrassment, and loss of control (about when or if to involve the police).

Another study (Campo, Poulos, \& Sipple, 2005) applied the HBM to hazing. Hazing is under-reported for a number of reasons, but 20 to 50 hazing-related deaths are reported from college campuses in the United States each year. Around a third (36\%) of the college students surveyed reported that they were involved in activities that constitute hazing. Most occurred within fraternities or varsity athletic programs. The most commonly reported hazing activities were drinking contests/games and sleep deprivation. Overall, students agreed that hazing was harmful, but were neutral about perceived benefits including: 1) their susceptibility to harm; 2) whether their friends approved of their activities; 3) the enjoyment of hazing activities; 4) and the belief that hazing builds group cohesion. Three factors that best predicted students' ability to remove themselves from potentially dangerous situations included having friends outside the organization, perceived likelihood of being harmed, and friends within the organization that support the decision. Perceived susceptibility fits well with the HBM. The other two elements are purely social. If students will maintain friendships both inside and outside the organization, they are better able to withstand the pressure to endure hazing.

\section{Hypotheses}

Based on the preceding review of the literature, the following hypotheses are posited:

H1: Medical professionals will believe patients are more affected than themselves by media depictions of IPV (Thirdperson perception).

H2: TPP will increase as elements of the HBM (perceived susceptibility, perceived severity, perceived benefits, and perceived barriers) increase.

In order to test the behavioral component of TPP, an additional hypothesis is posited:

H3: Beliefs about community attitudes and willingness to intervene in IPV cases will be predicted by TPP.

\section{Method}

\section{Participants}

A total of 316 medical professionals participated in the study, between July 2009 and June 2010. Participants were medical students/interns (69\%), nurses (24\%), and administrators (7\%) in Pennsylvania. Individuals were targeted for inclusion because they either currently screened patients for IPV or were preparing to do so in the future. The sample was $89 \%$ female, $90 \%$ Caucasian, ranging in age from 27 to $66(X=32.1, S D=$ 13.3). The sample is representative of people enrolled in nursing programs in this region.

\section{Procedures}

Participants were recruited by a women's center providing IPV training to improve screening quality in the region. All study measures were completed prior to the training to prevent priming or skewing results. Participation was voluntary. In some cases, participants did not respond to all survey items. The most common items skipped were age and race. Missing cells were not including in analysis, resulting in a lower $\mathrm{N}$ for some tests. The study was approved by the university's IRB for use with human subjects. APA ethical guidelines were strictly adhered to.

\section{Materials}

Third-person perception was measured with a standard instrument (Rubin, Rubin, Graham, Perse, \& Seibold, 2009). Participants completed the following two items on a Likert-type scale ( 1 = not at all; 7 = very much): 1 ) how much are patients affected by media depictions of intimate partner violence? 2) how much are YOU affected by media depictions of intimate partner violence? A measure of TPP is obtained by subtracting the "other" rating from the "self" rating. TPP is indicated by a negative mean, which can be interpreted as the perception that others are more influenced than oneself.

Two items measured beliefs about community attitudes and willingness to intervene in IPV cases: "Most community members are willing to intervene in cases of spousal abuse once they become aware." "Most community members do not approve of spousal abuse." Both items were measured on a Likert-type scale ranging from strongly disagree (1) to strongly agree (7).

The Health Belief Model was measured through a series of questions, each measured on a Likert-type scale ranging from strongly disagree (1) to strongly agree (7): 1) perceived susceptibility: "Compared to other people my age in the US, my chances of being abused by an intimate partner are lower"; 2) 
perceived severity: "The physical impact of domestic abuse can be severe;" the emotional impact of domestic abuse can be severe." These two items were summed; 3) perceived benefits: "Domestic violence services available to patients at the hospital are useful and easily accessible"; 4) perceived barriers: "There are numerous obstacles which impact a victim's ability to leave their situation.” All of the items were summed to create a HBM scale. The resulting scale demonstrated low to moderate internal consistency $(\alpha=.71)$.

Participants also self-reported their age, race, and gender.

\section{Results}

Table 1 displays zero-order correlations among the variables predicting third-person perception. Doing so allows readers to compare and weigh the relationships across variables. Standard multiple regression was used to identify the predictors of TPP. Analysis of residual plots indicates that assumptions regarding normality, linearity and homoscadasticity were met. Table 2 displays the regression analysis.

H1 predicted TPP, that medical professionals believe they are less likely than patients to be influenced by media portrayals of IPV. TPP is indicated by a group mean significantly less than zero. As predicted, Participants believed they $(X=2.2, S D$ $=1.1$ ) were less influenced by news coverage of crime than others $(X=3.4, S D=1.1), t(301)=2.1, p<.000$. H1 was supported. The finding is consistent with the literature. No relationship between TPP and demographic variables (age, gender, and race) was predicted, and none emerged. Because TPP is indicated by a negative mean, signs are reversed in the table for ease of interpretation.

H2 predicted TPP would increase as elements of the Health Belief Model (perceived susceptibility, perceived severity, perceived benefits, and perceived barriers) increased. While a significant relationship between the HBM and TPP is indicated on Table 1, the relationship fails to explain any unique variance in the regression model. A single HBM element, perceived susceptibility, emerges as the strongest predictor of TPP: $41.4 \%$ of participants agreed or strongly agreed with the statement,
"Compared to other people my age in the US, my chances of being abused by an intimate partner are lower." Nearly one third (30.2\%) disagreed or strongly disagreed with the statement. The remaining $11.8 \%$ responded in the middle of the scale. The remaining components of the HBM were not significantly related to TPP. H2 was partially supported.

H3 tested the attitudinal/behavioral component of TPP, predicting a relationship between TPP and beliefs about attitudes and willingness to intervene in IPV cases. While most participating medical professionals (84.3\%) agreed or strongly agreed that most community members do not approve of IPV, less than one fourth $(23.1 \%)$ believe most community members are willing to intervene in IPV cases. TPP predicts beliefs about willingness to intervene, but not beliefs about attitudes. H3 is partially supported.

\section{Discussion}

The purpose of the current study was to examine third-person perception within the context of a public health issue (intimate partner violence) and to explore theoretical linkage between TPP and the health belief model.

Nurses and medical interns were selected to participate in the study, because they are likely to screen incoming patients for IPV. Findings suggest medical professionals do exhibit TPP, believing they are less influenced than are patients by media depictions of IPV. Previous findings indicate that people who exhibit TPP engage in less information seeking about the topic and may be less critical viewers. This is especially problematic in the case of IPV, because medical dramas, police dramas, and court dramas tend to showcase extreme cases for dramatic effect. Ultimately, misperceptions gleaned from TV could negatively impact effective screening of IPV and the quality of patient care. In this case, TPP was related to beliefs about community members' willingness to intervene in IPV cases. Between advertisements, public service announcements, news coverage, and entertainment programs, there is a rich area of health-related messages yet to be explored in future research.

In terms of the Health Belief Model, one element, perceived

Table 1.

Zero-order correlations among variables predicting third-person perception.

\begin{tabular}{|c|c|c|c|c|c|c|c|}
\hline & 2 & 3 & 4 & 5 & 6 & 7 & 8 \\
\hline 1. ТРP & $.24 * *$ & $.18^{*}$ & $.18^{*}$ & .09 & .09 & .08 & .05 \\
\hline 2. HBM/Susceptibility & - & .14 & $.16 *$ & .14 & .01 & .04 & .06 \\
\hline 3. HBM & & - & $.60 * *$ & $.75^{* *}$ & $.67^{* *}$ & $.24 * *$ & $.18^{*}$ \\
\hline 4. Intervention & & & - & $.21^{* *}$ & .03 & .13 & .09 \\
\hline 5. Attitude & & & & - & $.36 * *$ & .10 & $.19 *$ \\
\hline 6. HBM/Severity & & & & & - & .06 & .13 \\
\hline 7. HBM/Benefits & & & & & & - & $.33^{* *}$ \\
\hline 8. HBM/Barriers & & & & & & & - \\
\hline
\end{tabular}

Note. ${ }^{*} p<.05,{ }^{* *} p<.01 .1$ ) TPP (Third-person perception); 2) HMB/Susceptibility (Health Belief Model, Susceptibility to IPV); 3) HBM (Health Belief Model); 4) Intervention (Perceived willingness of community members to intervene in IPV cases); 5) Attitude (Perceived approval of community members of IPV); 6) HBM/Severity (Severity of IPV for victims); 7) HBM/Benefits (Benefits of hospital resources for IPV victims); 8) HBM/Barriers (Barriers to victims for IPV services). 
Table 2.

Summary of linear regression analysis for variables predicting thirdperson perception.

\begin{tabular}{cccc}
\hline & \multicolumn{3}{c}{ Adj. $r^{2}=.10$} \\
$N=306$ \\
\hline Predictor & B & SE B & $\beta$ \\
HBM/Susceptibility & .11 & .06 & $.16^{*}$ \\
HMB & .04 & .10 & .08 \\
\hline
\end{tabular}

$* p<.05$

susceptibility, emerged as a predictor of TPP. A similar construct, optimistic bias, has been linked with TPP in the past (Chapin, 2000; Salwen \& Dupagne, 2003). Perceived susceptibility and perceived severity tend to be the strongest predictors of attitudes and behaviors in the HBM literature. In this case, $98.7 \%$ agreed or strongly agreed that the emotional impact of IPV is severe and 98.1 agreed or strongly agreed that the physical impact of IPV is severe. The lack of variance may explain the insignificant finding. While it was not the focus of this paper, it's interesting to note that both community attitudes about IPV and willingness to intervene were more strongly related to the HBM than to TPP. The finding solidifies the value of the model for IPV scholars and advocates. It also provides the groundwork for future linkages between the HBM and TPP literatures.

A number of limitations should be considered before interpreting the results of this study. The study is based on a convenience sample of medical personnel gathered for training on intimate partner violence. Test measures were collected prior to the training to limit skewed responses, but participants were aware of the topic and some priming may have occurred.

\section{Conflict of Interest Statement}

None to report.

\section{References}

Boyle, M., McLeod, D., \& Rojas, H. (2008). The role of ego enhancement and perceived message exposure in third-person perception judgments concerning violent video games. American Behavioral Scientist, 52, 165-185. doi:10.1177/0002764208321349

Campo, S., Poulos, G. \& Sipple, J. (2005). Prevalence and profiling: Hazing among college students and points of intervention. American Journal of Health Behavior, 29, 137-149.

Carlson, A., Campbell, J., Garza, M., Campo, P., Dienemann, J., Kub, J., Jones, A., \& Lloyd, D. (2006). Domestic violence in the military: Women's policy preferences and beliefs concerning routine screening and mandatory reporting. Military Medicine, 171, 729-735.

Chapin, J. (2000). Third-person perception and optimistic bias among urban minority at-risk youth. Communication Research, 27, 51-81. doi:10.1177/009365000027001003

Chia, S. (2009). When the east meets the west: An examination of third-person perceptions about idealized body image in Singapore. Mass Communication and Society, 12, 423-445. doi:10.1080/15205430802567123

Chia, S., \& Wen, N. (2009). College men's third-person perceptions about idealized body image and consequent behavior. Paper presented at the annual meeting of the International Communication
Association.

Cho, H., \& Boster, F. (2008). First and third person perceptions on anti-drug ads among adolescents. Communication Research, 35, 169-189. doi:10.1177/0093650207313158

Chock, T., Fox, J., Angelini, J., Lee, S., \& Lang, A. (2007). Telling me quickly: How arousing fast-paced PSAs decrease self-other distinctions. Communication Research, 34, 618-636. doi:10.1177/0093650207307900

Coe, K. Tewksbury, D., Bond, B., Drogos, K., Porter, R., Yahn, A., \& Zhang, Y. (2008). Hostile news: Partisan use and perceptions of cable news programming. Journal of Communication, 58, 201-219. doi:10.1111/j.1460-2466.2008.00381.x

Cohen, J., \& Weimann, G. (2008). Who's afraid of reality shows? Exploring the effects of reality shows and the concern over their social effects on willingness to censor. Communication Research, 35, 382-397. doi:10.1177/0093650208315964

Conners, J. (2005). Understanding third-person effect. Communication Research Trends, 24, 3-22.

Davison, W. (1983). The third-person effect in communication. Public Opinion Quarterly, 47, 1-15. doi:10.1086/268763

Day, A. (2008). Out of the living room and into the voting booth: An analysis of corporate public affairs advertising under the third-person effect. American Behavioral Scientist, 52, 243-260. doi:10.1177/0002764208321354

Frederick, E., \& Neuwirth, K. (2008). The second-person effect and its role in formation of active issues publics. Mass Communication and Society, 11, 514-538. doi:10.1080/15205430802368613

Golan, G., Banning, S., \& Lundy, L. (2008). Likelihood to vote, candidate choice, and the third-person effect. American Behavioral Scientist, 52, 278-290. doi:10.1177/0002764208321356

Golan, G., \& Day, A. (2008). The first-person effect and its behavioral consequences: A new trend in the twenty-five year history of third-person effect research. Mass Communication and Society, 11, 539-556. doi:10.1080/15205430802368621

Jeffres, L., Neundorf, K., Bracken, C., \& Atkin, D. (2008). Integrating theoretical traditions in media effects: Using third-person effects to link agenda-setting and cultivation. Mass Communication and Society, 11, 470-491. doi:10.1080/15205430802375303

Lewis, I., Watson, B., \& Tay, R. (2007). Examining the effectiveness of physical threats in road safety advertising: The role of the third-person effect, gender and age. Transportation Research, 10, 48-60.

Lin, P., Simoni, J. \& Zemon, V. (2005). The health belief model, sexual behaviors, and HIV risk among Taiwanese immigrants. AIDS Education and prevention, 17, 469-483. doi:10.1521/aeap.2005.17.5.469

Rubin, B., Rubin, A., Graham, E., Perse, E., \& Seibold, D. (2009). Communication research measures II: A sourcebook. New York: Routledge.

Salwen, M., \& Dupagne, M. (2003). News of Y2K and experiencing Y2K: Exploring the relationship between the third-person effect and optimistic bias. Media Psychology, 5, 57-82. doi:10.1207/S1532785XMEP0501_3

Sigal, B. (2009). The third-person effect in Israeli women's attitude to TV commercials and their images. Paper presented at the annual meeting of the International Communication Association.

Wei, R., Lo, V., \& Lu, H. (2008). Third-person effects of health news: Exploring the relationships among media exposure, presumed media influence, and behavioral intentions. American Behavioral Scientist, 52, 261-277.

Zhao, X., \& Cai, X. (2008). From self-enhancement to supporting censorship: The third-person effect process in the case of Internet pornography, Mass Communication and Society, 11, 437-462. doi:10.1080/15205430802071258

Zhong, Z. (2009). Third-person perceptions and online games: A comparison of perceived antisocial and prosocial game effects. Journal of Computer-Mediated Communication, 14, 286-306.

doi:10.1111/j.1083-6101.2009.01441.X 